\title{
A pandemia intramuros: (in)comunicabilidade de mulheres encarceradas em João Pessoa-PB ${ }^{1}$
}

\author{
The pandemic in prison: (in) communicability of women jailed, in João \\ Pessoa / PB
}

\author{
JOSILENE RIBEIRO DE OLIVEIRA \\ Doutora em Sociologia pela Universidade Federal e Pernambuco \\ (2018) e pela Université Franche-Comté \\ josilene.ribeiro@academico.ufpb.br \\ ROSILENE OLIVEIRA ROCHA \\ Doutora em Sociologia - Programa de Pós-Graduação em \\ Sociologia (PPGS) da Universidade Federal de \\ Pernambuco/UFPE \\ rosilene.rocha@ufpe.br \\ ANNE KELLY MACÊDO DE ABREU \\ Mestre pelo Programa de Pós-graduação em Jornalismo da \\ Universidade Federal da Paraíba (UFPB). \\ kellyradialista@hotmail.com
}

\section{RESUMO}

Este artigo versa sobre os impactos da Pandemia de COVID-19 para as mulheres encarceradas na Penitenciária Feminina Maria Júlia Maranhão, localizada em João Pessoa/PB. Trata-se de um estudo de natureza qualitativa, metodologicamente embasado em entrevistas semiestruturadas e conversas informais, realizadas por telefone, junto a representantes e funcionários da unidade prisional; Revisão bibliográfica na literatura específica; Pesquisa documental junto a publicações oficiais do Governo do Estado da Paraíba, do Conselho Nacional de Justiça e Departamento Penitenciário Nacional e levantamento de informação em sites de notícias e noticiários televisivos. A abordagem em tela chama atenção para os gargalos históricos observados na interseccionalidade entre as relações de gênero, as dimensões de "raça/cor" e de classe, além de outros marcadores sociais, no contexto do Sistema Prisional Brasileiro. Os resultados permitem compreender a evolução dos casos de COVID-19 nas penitenciárias paraibanas, os impactos da Pandemia e as mudanças provocadas sobre o cotidiano de mulheres encarceradas.

Palavras-Chaves: Mulheres. Prisões. Pandemia. Comunicação. Direitos Humanos. Política Prisional.

\section{ABSTRACT}

This paper analyses the impacts of the COVID-19 Pandemic for women incarcerated at the Maria Júlia Maranhão Penitentiary, located in João Pessoa/PB/Brazil. It is a qualitative study, methodologically based on semi-structured interviews and informal conversations, conducted by telephone, with representatives and employees of that prison unit; Literature review; Documentary research with official publications of the Government of the State of Paraíba, the National Council of Justice and the National Penitentiary Department and gathering information in the news sites and television news. Our

\footnotetext{
${ }^{1}$ Artigo recebido em 30.09.2020 e aprovado em: 20.10.2020.
} 
Rev. Interd. em Cult. e Soc. (RICS), São Luís, v. 6, n. 2, p. 120-141, jul./dez. 2020

ISSN eletrônico: $2447-6498$

study also aims to show the historical challenges about the intersectionality between gender relations, the dimensions of "race/color", social classes and other social markers, in the reality of the Brazilian Prison System. The results of this study show the evolution of covid-19 cases in the Paraíba penitentiaries, the impacts of the Pandemic and the changes brought about in the daily lives of women in prison.

Keywords: Women. Prision. Pandemic. Comunication. Human rights. Prison Policy.

\section{INTRODUÇÃO}

A Pandemia de COVID-19 trouxe à tona muitas tensões e questionamentos sobre nosso estilo de vida e sobre nossa capacidade coletiva e individual de lidar com as incertezas, as perdas e o medo em relação ao futuro, além de evidenciar a dependência tecnológica e o papel determinante da comunicação digital na sociedade contemporânea. Por todo o mundo o "isolamento social" (distanciamento social) tornou-se uma medida preventiva à propagação do vírus, aliando-se à prática de higienização frequente de ambientes, das mãos, dos corpos, das roupas etc. Paralelamente, o uso das tecnologias de informação e comunicação colocaram-se como essenciais seja para viabilizar práticas de trabalho (teletrabalho/home office), seja para a interação social à distância. Contudo, mesmo gozando de liberdade de circulação, acesso à informação e às tecnologias, e de autonomia de decisão, não há dúvidas de que a adaptação a essa nova realidade e a adoção das recomendações sanitárias na vida cotidiana tornaram-se um grande desafio para qualquer pessoa.

Nesse contexto, dirigimos nosso olhar na busca de compreender os impactos da Pandemia para as pessoas privadas de liberdade, que já se encontram em situação de vulnerabilidade e "isolamento social". Vale lembrar que para estas pessoas o isolamento (no cárcere) não é uma escolha voluntária, mas, sim, uma pena imposta pelo Estado, e que não assegura a preservação da saúde ou a manutenção do distanciamento mínimo necessário recomendado pelos órgãos de saúde. Com efeito, o cárcere implica justo o contrário, isto é, o convívio forçado com outras pessoas nos poucos metros quadrados que formam uma cela e encerrada por muros concretos e simbólicos. Na grande maioria das vezes, trata-se de uma cela minúscula e instalações onde as pessoas presas se encontram privadas de informação e contato com o mundo exterior, da possibilidade de se cuidar e da liberdade de se comunicar com familiares e amigos.

Não há dúvidas que, dentro de tais circunstâncias, mulheres e homens encarcerados tiveram suas precárias condições de vida agravadas, passando a conviver com o medo, a 
Rev. Interd. em Cult. e Soc. (RICS), São Luís, v. 6, n. 2, p. 120-141, jul./dez. 2020 ISSN eletrônico: 2447-6498

escassez de notícias de seus parentes e até mesmo de itens de alimentação e higiene pessoal trazidos por estes, quando das visitas. $\mathrm{O}$ endurecimento das medidas de isolamento de encarcerados e encarceradas pelo Estado concretizou-se sob o argumento de salvaguardar vidas. "No entanto, nem todos os aspectos da atuação estatal foram plenamente alcançados por essa necessidade de proteção à saúde”, destaca Pimentel (2020, p. 307), dado o número de pessoas infectadas em todo Sistema Prisional do país.

Até o dia 14 de setembro do corrente ano, 34.961 casos de COVID-19 já haviam sido confirmados no Sistema Prisional Brasileiro, sendo 25.617 deles em pessoas presas e 9.344 em servidores (policiais penais e outros profissionais que atuam no sistema), perfazendo o total de 192 vítimas fatais (110 pessoas privadas de liberdade e 82 servidores), conforme dados oficiais do Conselho Nacional de Justiça (CNJ) e do Departamento Penitenciário Nacional (DEPEN).

Os primeiros dois casos de COVID-19 entre pessoas presas foram registrados, oficialmente, em 08 de abril. Um desses casos acometeu uma pessoa que cumpria a pena em regime semiaberto e que supostamente se infectou ao sair da unidade para trabalhar, em um presídio no estado do Pará. Entretanto, segundo dados oficiais, exatamente seis dias antes deste caso, um servidor que trabalha em uma outra unidade prisional foi infectado (CNJ/DEPEN, 2020). Vinte dias depois das duas pessoas presas infectadas, em 28 de abril, 107 casos já haviam sido notificados, conforme o Painel de Monitoramento da COVID-19 no Sistema Prisional (DEPEN, 2020). Esses dados constituem uma pista e uma evidência bastante contundente sobre os fluxos da contaminação e a vulnerabilidade das pessoas privadas de liberdade, posto que para cada servidor contaminado, praticamente três pessoas presas já foram acometidas pela doença, cujas sequelas sobre o organismo ainda estão sendo estudadas.

Com objetivo de contribuir com o debate e explicitar as particularidades da situação de vulnerabilidade das pessoas encarceradas na Paraíba, neste trabalho discutimos as implicações da pandemia de COVID-19 a partir das mudanças na rotina das detentas mantidas na Penitenciária de Recuperação Feminina Maria Júlia Maranhão, em João Pessoa/PB. O objetivo do estudo é traçar um panorama do impacto da pandemia no sistema carcerário paraibano e analisar os desdobramentos dessa crise, considerando os direitos fundamentais das pessoas presas no que tange a saúde e a comunicação, especialmente das mulheres. 
Rev. Interd. em Cult. e Soc. (RICS), São Luís, v. 6, n. 2, p. 120-141, jul./dez. 2020

ISSN eletrônico: $2447-6498$

\section{CONTRADIÇÕES DO SISTEMA PRISIONAL E O CENÁRIO BRASILEIRO}

Muito embora estejamos temporalmente distantes daqueles contextos históricos nos quais esquartejamentos e apedrejamentos ocorriam em praça pública, conforme abordado por Michel Foucault em "Vigiar e Punir", talvez nossa lógica de punição, agora, em pleno ano de 2020, não esteja tão distante e nem seja tão diferente daquelas práticas do século XVIII. Na modernidade as configurações da prisão assimilaram a privação de liberdade como 'castigo', 'sanção' aplicada em decorrência da violação de um ideal de ordem socialmente construído e pactuado junto ao Estado. Muda-se o cenário, a forma, mas a lógica limitada ao suplício como "melhor" castigo prevalece praticamente imutável ao longo dos séculos.

A busca pela produção dos chamados 'corpos dóceis', a imposição de padrões de comportamento e normas de conduta, que caracterizam a sociedade moderna, são reproduzidos de forma rígida e sob vigilância dentro dos estabelecimentos prisionais. Trata-se de uma "cultura institucional punitiva, cristalizada historicamente nas práticas de disciplina e controle prisional" (BARROS, REIS BARROS, MÁXIMO, 2020, p. 274).

Atendo-se a uma função estritamente punitiva da prisão, em detrimento de medidas pautadas na socialização desses(as) presos(as) para além do ideal de punição, o Estado reforça a "natureza contraditória da ideologia penal da reinserção", conforme aborda Baratta (1999, p. 186). Ainda de acordo com o referido autor, "toda técnica pedagógica de reinserção do detido choca contra a natureza mesma desta relação de exclusão. Não se pode, ao mesmo tempo, excluir e incluir" Baratta (1999, p. 186). O que o autor coloca em relevo é a impossibilidade de o sistema prisional realizar seu papel de reintegrar os apenados à sociedade, tendo em vista que o isolamento no cárcere não gera os benefícios pretendidos pelo Estado, em razão das características e disfunções do sistema carcerário. Para o referido autor, seria incoerente pensar que a exclusão, como parte do processo de "reeducação", pudesse ter e gerar como objetivo final a inclusão.

Levando em consideração as condições do Sistema Prisional, há um acúmulo de agravantes em torno dos quais a realidade vivenciada pelas pessoas encarceradas vai sendo construída no cenário brasileiro. As condições precárias das unidades prisionais, com destaque para superlotação das celas, para insuficiência de profissionais de assistência à saúde dos encarcerados, para as falhas na aplicação da legislação e da política prisional nacional, o que resulta em ambientes insalubres e inseguros, que levam a muitas denúncias de violação dos Direitos Humanos (IPEA, 2015). 
Rev. Interd. em Cult. e Soc. (RICS), São Luís, v. 6, n. 2, p. 120-141, jul./dez. 2020 ISSN eletrônico: 2447-6498

Paralelamente a isso, registra-se que Brasil possui a terceira maior população carcerária do mundo, ficando atrás apenas de países como Estados Unidos e China. Conforme ilustram os Gráficos 01 e 02, percebe-se que o percentual de crescimento populacional apresentou uma tendência de queda no período compreendido entre 2000 e 2019, com os maiores picos de aumento nos anos de 2003, 2006 e 2015, chegando a 1,49\% no ano de 2019. Já a taxa de aprisionamento de pessoas por ano, apresentou crescimento ascendente, saltando de $137 \%$ no ano 2000, passando para 260\% em 2010 e atingindo a marca de 359,4\% em 2019. Dados do Departamento Penitenciário Nacional/ DEPEN (2019) mostram, ainda, que só no período de Julho a Dezembro de 2019 o total de pessoas presas foi de 6.198 no país. Deste total, 268 são do sexo feminino e 6.997 do sexo masculino, representando 3,69\% e 96,31\%, respectivamente, nesse período.

Gráfico 01: Crescimento da população no Brasil. (\%)

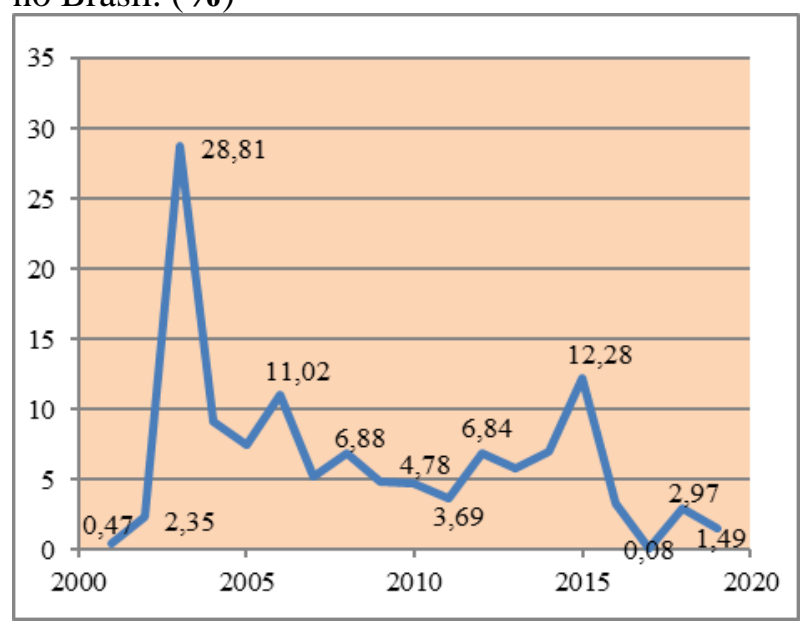

Gráfico 02: Crescimento da população carcerária no Brasil. (\% por 100 mil)

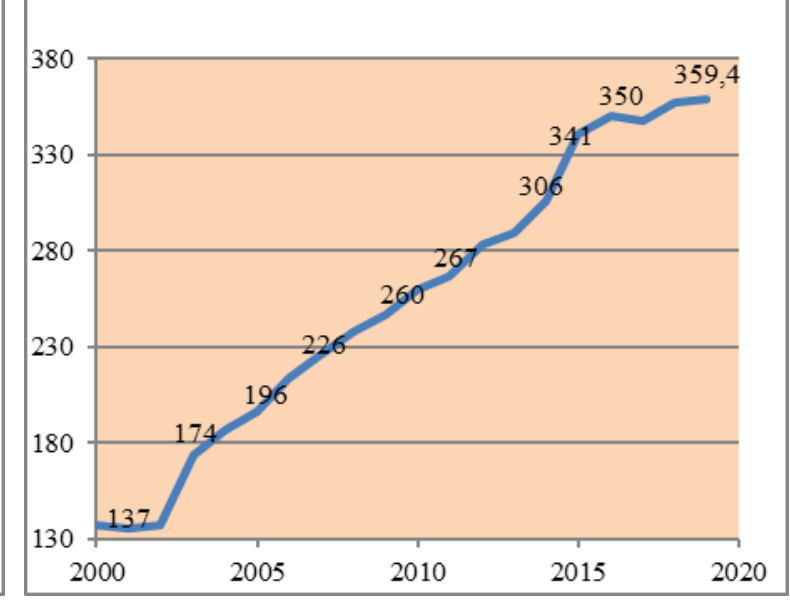

Fonte: Gráficos produzidos a partir de dados do Departamento Penitenciário Nacional (DEPEN, 2019).

Até 14 de Fevereiro de 2020, conforme site do Ministério da Justiça e Segurança Pública, havia no país um total de "773.151 pessoas privadas de liberdade em todos os regimes" (MJSP, 2020). Destaca-se as dimensões de raça e classe social na composição do perfil dessa população aprisionada, haja vista que 64\% dos(as) presos(as) são negros(as). Além disso, a cada "100 pessoas assassinadas no Brasil, 71 são negras" (MDH, 2018).

Numa realidade marcada por exclusão, desigualdades, injustiças sociais e corrupção, por exemplo, os gargalos observados no Sistema Prisional Brasileiro vão se somando a outras violações de direitos, historicamente naturalizadas em nossa Sociedade. Tal realidade demonstra, também, as consequências das práticas socioculturais de uma sociedade estruturada em relações de poder, dominação e hierarquizações sociais. Uma sociedade que reproduz, 
Rev. Interd. em Cult. e Soc. (RICS), São Luís, v. 6, n. 2, p. 120-141, jul./dez. 2020 ISSN eletrônico: 2447-6498

cotidianamente, diversos tipos de discriminação, de intolerância entre seus membros e de desrespeito à sua própria Constituição Federal. Sociedade esta, na qual se observa uma "desigual distribuição social da criminalização" (BARATA, 1999, p.15).

Esse quadro estrutural da sociedade brasileira deixa transparecer as lacunas de um processo de civilização inacabado, interrompido, postergado ou perdido em alguma etapa da relação entre Sociedade e Estado. Tal situação reforça a cultura de punição e tortura tanto corporal quanto psicológica que está impregnada na concepção social de encarceramento. Um estudo, fruto de uma parceria entre o Departamento Penitenciário Nacional e o Programa das Nações Unidas para o Desenvolvimento, sobre o panorama da reincidência criminal no Brasil, destaca que no interior de muitos estabelecimentos prisionais há "um conflito permanente entre a garantia dos direitos e a propensão à contenção total das pessoas custodiadas, evitando-se ao máximo sua movimentação interna pelos ambientes prisionais" (BRASIL-PNUD, 2016, p. 150).

Corroborando com tais fatos, as pesquisadoras Barros, Reis Barros e Máximo (2020, p. 271) afirmam: “intramuros, a população encarcerada é submetida a irregularidades $e$ violações de direito de toda ordem”. Nessa perspectiva, é preciso vencer, ainda, a cultura da violação de direitos humanos, historicamente naturalizada em nosso país. Além disso, deve-se considerar que o encarceramento implica em comprometimento significativo do processo de socialização, das interações, das sociabilidades, da comunicação dessa pessoa para com seus semelhantes. Haja vista que o isolamento físico causado pelo encarceramento se traduz em uma escassa comunicação não apenas com o mundo e com a família, mas, em suma, privação de comunicação interpessoal, inibindo o desenvolvimento saudável da pessoa humana em razão da perda da 'liberdade substantiva', isto é, daquilo que Sen define como condição para o indivíduo ter uma "vida que tenha razão de valorizar", conforme Sen (2000, p. 94).

Ao discutirem o direito à comunicação e o acesso dos presos à internet, Rudnicki e Veeck (2018), sugerem que a limitada rede social do apenado dentro da prisão - restrita ao convívio com os demais apenados, agentes penitenciários e eventuais visitas de familiares e advogados - acarreta sequelas que vão influenciar sua vida durante e após o encarceramento. Para eles, o afastamento da sociedade livre implica perda ou, no mínimo, diminuição dos laços sociais com amigos e familiares, além de dificuldade de acompanhamento das mudanças sociais, com a consequente a perda de hábitos e disposições para estabelecer relacionamentos, resultando na estigmatização e "prisonização", conforme Hassemer (2005). 
Rev. Interd. em Cult. e Soc. (RICS), São Luís, v. 6, n. 2, p. 120-141, jul./dez. 2020 ISSN eletrônico: $2447-6498$

Destaca-se que o direito à comunicação de pessoas presas está amparado na legislação nacional e internacional. No âmbito internacional, segundo as Organizações das Nações Unidas, "os prisioneiros devem ter permissão, sob a supervisão necessária, para comunicarem-se periodicamente com suas famílias e amigos" (BRASIL, 2009, p. 19). Além disso, tal entidade define que "o tratamento de prisioneiros deve enfatizar não a sua exclusão da comunidade, mas sua participação contínua nela" (ONU, 2009, p. 25).

Por sua vez, a Lei de Execução Penal (LEP) brasileira, Lei n ${ }^{0}$ 7.210/84, que normatiza o processo de execução criminal e garante às pessoas presas e internadas a devida assistência, além de dar outras garantias legais, embora defina como falta disciplinar a posse de instrumentos de comunicação com outros detentos ou com ambiente exterior, apresenta o contato do preso com o exterior como recurso importante para sua futura reintegração à sociedade. Portanto, cabe ao Estado lançar medidas tanto para assegurar tais direitos quanto para fiscalizar seu descumprimento.

No entanto, percebe-se que, mesmo em condições de 'normalidade', frequentemente, o direito à visita de familiares não se concretiza, pois as famílias de muitos(as) apenados(as) não têm condições financeiras para arcar com os custos do deslocamento até a unidade prisional, que, muitas vezes, fica distante de seus locais de residência. Ademais, o uso de correspondências escritas, por sua vez, caiu em desuso, não sendo substituído automaticamente por meios de comunicação digital, haja vista que, muitas unidades prisionais não possuem equipamentos, profissionais e/ou treinamento para viabilizar a interação por meio de tais recursos.

A situação é ainda mais dramática entre as mulheres encarceradas, pois conforme dados do Relatório Temático Sobre Mulheres Privadas de Liberdade, elaborado pelo Departamento Penitenciário Nacional/DEPEN, as presas costumam ter menos visitas do que homens vivendo na mesma situação (DEPEN, 2019). Ademais, a proibição de visitas familiares, de advogados e qualquer outro tipo de contato com o mundo externo devido a pandemia de COVID-19 coloca as detentas (e detentos) em situação de incomunicabilidade, constituindo-se em mais uma das violações aos direitos da população carcerária, além de causar enorme sofrimento e angústia por parte dos familiares e dos presos e presas, que estão sem notícias, sem amparo, sem onde e a quem recorrer, como destacado pelo Conselho Nacional de Justiça (CNJ, 2020a). Chegamos, pois, aos pontos de intersecção dos temas 
Rev. Interd. em Cult. e Soc. (RICS), São Luís, v. 6, n. 2, p. 120-141, jul./dez. 2020 ISSN eletrônico: 2447-6498

apreciados neste estudo: as relações de gênero e as condições do cárcere em meio a um contexto de Pandemia ocasionada pelo novo Coronavírus.

\section{MULHERES E CÁRCERE: UMA INTERSECÇÃO DE GARGALOS HISTÓRICOS}

Dentre os desafios que se impõem aos avanços civilizatórios na agenda Republicana brasileira, destaca-se a dificuldade histórica de vencermos, também, a cultura da subordinação de gênero em nossa sociedade. Embora muitas conquistas possam ser elencadas no histórico de lutas em prol dos direitos das mulheres, a luta contra as discriminações de gênero enfrenta, ainda, resistência dentro das próprias instâncias de poder político instituídas no país.

Apesar das mulheres representarem quase $51 \%$ da população do Brasil (IBGE, 2010), quando se observa a incapacidade do Estado Brasileiro em legitimar os direitos das mulheres, em implementar e consolidar, a contento, políticas públicas para este segmento (que, diuturnamente, esbarra na reprodução de machismo, misoginia e patriarcalismo em nossa realidade), podemos ter uma pálida noção do que está em pauta quando falamos em Políticas Públicas para mulheres encarceradas.

Essa intersecção que sobrepõe a realidade do Sistema Prisional brasileiro com a realidade vivenciada por mulheres e meninas em nosso país é um dos pilares que justificam a necessidade de estudos focados em trazer à tona as múltiplas vulnerabilidades por elas enfrentadas, pelo fato de serem mulheres. Nesses termos, o encarceramento de mulheres figura como um segmento à margem de outras margens. Observa-se uma sobreposição de desafios históricos como a demanda por direitos, uma sobreposição de estigmas e de pautas que se entrelaçam numa luta maior: a luta por Direitos Humanos.

Ressalta-se que as prisões femininas brasileiras não são planejadas para mulheres, algo apontado por diversos pesquisadores do tema, dentre os(as) quais: Moraes e Dalgalarrondo (2006), Wright (2006), Nana Queiroz (2015), Flores e Smeh (2018), Varella (2017), Perano (2019), Pimentel (2017, 2020), entre outros. Em geral, as unidades prisionais femininas reproduzem as mesmas práticas masculinizadas de controle sobre o corpo e são, arquitetônica e estruturalmente, o resultado de adaptações de prisões masculinas (PIMENTEL, 2020).

Cabe mencionar o estudo que inaugura as discussões acerca das condições das mulheres no cárcere realizado por Julita Lemgruber num Instituto Penal do Rio de Janeiro. Intitulada "Cemitério dos Vivos: análise sociológica de uma prisão de mulheres", a obra escrita entre 1976 e 1978 continua dotada de sentido na atual realidade do sistema prisional 
Rev. Interd. em Cult. e Soc. (RICS), São Luís, v. 6, n. 2, p. 120-141, jul./dez. 2020 ISSN eletrônico: 2447-6498

brasileiro, sobretudo, no tocante à condição das mulheres diante da construção sociocultural das relações de gênero e sua fusão com os ideais de punição encrustados nas concepções sociais sobre prisões em nossa sociedade.

Ao traçar o perfil das mulheres encarceradas, Lemgruber (1999) termina por confirmar a seletividade do sistema punitivo no Brasil, que incide majoritariamente sobre os segmentos sociais mais vulneráveis, estigmatizados e marginalizados. Nesse sentido, Pimentel (2020), destaca que, no caso das mulheres, a condição de vulnerabilidade antecede o próprio cárcere, considerando-se o perfil da população carcerária feminina no país, predominantemente constituído por mulheres com baixa escolaridade, pobres, negras e pardas.

Relatórios de inspeção do sistema penitenciário realizadas pelo Conselho Nacional de Política Criminal e Penitenciária/CNPCP, em função da CPI do sistema carcerário, em 2008, ressaltam que "as prisões seguem destinadas a pobres, negros e desvalidos e se assemelham às masmorras medievais”, apontam Barros, Reis Barros e Máximo (2020, p. 272). Segundo as autoras, as prisões "simbolicamente constituem-se em depósito de dejetos, do que é desprezível, degradante e como locais destinados a tratar dos resíduos da sociedade". Em síntese, o encarceramento se constitui um instrumento legal para resolução de conflitos gerados pela sociedade e que ela não pode resolver, tais como: desigualdade, injustiça social e negação de direitos básicos. Trata-se, portanto, da exclusão da vida social daquelas pessoas que já são excluídas economicamente (PERANO, 2019).

Nas últimas décadas, vem se observando um crescimento expressivo do aprisionamento de mulheres no Brasil. As pesquisadoras Diuana, Corrêa e Ventura (2017, p. 728) sistematizaram os dados divulgados pelo Departamento Penitenciário Nacional e apontam que, "enquanto a população prisional masculina cresceu 220,2\%, entre os anos 2000 e 2014, o número de mulheres custodiadas no sistema penitenciário aumentou 567,4\%, no mesmo período".

Os dados mais recentes divulgados no sítio do Departamento Penitenciário Nacional, através do Levantamento de Informações Penitenciárias mostram que o "encarceramento feminino voltou a subir. Desde 2016, havia uma queda na quantidade de mulheres presas, nesse período chegou a ser 41 mil mulheres. Em 2018, foram contabilizadas 36,4 mil mulheres e, em dezembro de 2019, aumentou para 37,2 mil mulheres". (BRASIL-INFOPEN, 2020). 
Rev. Interd. em Cult. e Soc. (RICS), São Luís, v. 6, n. 2, p. 120-141, jul./dez. 2020

ISSN eletrônico: $2447-6498$

Do total de mulheres cumprindo pena privativa de liberdade no Brasil, registra-se que 45\% delas estão encarceradas sem condenação; 32\% foram sentenciadas em Regime Fechado; 16\% sentenciadas em Regime Semiaberto e 7\% em Regime Aberto. Dentre as principais causas dessas prisões, destaca-se o tráfico de drogas. Conforme INFOPEN Mulheres, cerca de $62 \%$ das mulheres sob pena privativa de liberdade são negras. Quanto à maior causa associada ao aprisionamento de mulheres no Brasil, destaca-se o tráfico de drogas. Cerca de "62\% das incidências penais pelas quais as mulheres privadas de liberdade foram condenadas ou aguardam julgamento em 2016, o que significa dizer que $3 \mathrm{em}$ cada 5 mulheres que se encontram no sistema prisional respondem por crimes ligados ao tráfico" (INFOPEN, 2017, p. $53)$.

Destaca-se o estudo de Lima et. all (2013), no qual chamam a atenção para o modo como a condição de cárcere vai se convertendo num "processo de mutilação do eu", de "morte civil" na medida em que as presas vivenciam a substituição do convívio familiar, a ausência de autonomia nesse contexto de encarceramento. Desse modo, espera-se que o Estado não venha a potencializar as injustiças e o histórico de violações de direitos que costumam marcar a trajetória de vida de mulheres encarceradas no Brasil.

\section{A PANDEMIA INTRAMUROS NA PARAÍBA}

\subsection{Medidas de enfrentamento à COVID-19 adotadas no Sistema Prisional paraibano}

A Secretaria de Administração Penitenciária da Paraíba (SEAP-PB) responde por 20 unidades penais, sendo oito (08) destas localizadas na capital - João Pessoa, e mais 59 cadeias públicas, distribuídas por diversos municípios do Estado (GOVERNO DO ESTADO DA PARÁIBA, 2020). Conforme dados da SEAP, até agosto de 2019, a população carcerária do estado compreendia 12.176 pessoas, somando-se aquelas em regimes ${ }^{2}$ fechado, semiaberto e aberto. Desse total, 11.717 (96,2\%) estavam em unidades penais para homens e $459(3,8 \%)$ para mulheres, adotando-se o critério biológico para separação dos dois grupos. Na época, apenas 352 pessoas, ou seja, 2,9\% cumpriam pena em regime aberto, isto é, em domicílio.

O Governo Estadual decretou situação de emergência em 14 de março de 2020 (Decreto $\mathrm{n}^{\circ}$ 40.134), e Calamidade Pública no dia 20 do mesmo mês, para todo território paraibano. Tomando como parâmetro as diretrizes do Conselho Nacional de Justiça (CNJ),

\footnotetext{
${ }^{2}$ A Lei de Execução Penal no 7.210 de 1984 define os regimes prisionais em: aberto, em que o condenado cumpre a pena de reclusão em sua casa; semiaberto, caracterizado pela permissão dado ao preso para sair durante o dia e retornar à noite para unidade penal; fechado, cuja execução da pena acontece em estabelecimento de segurança máxima ou média.
} 
Rev. Interd. em Cult. e Soc. (RICS), São Luís, v. 6, n. 2, p. 120-141, jul./dez. 2020

ISSN eletrônico: $2447-6498$

definidas na Recomendação n. 62, de 17 de março de 2020 (posteriormente atualizada pela Recomendação n. 68 de 17/06/2020) e a Portaria Interministerial $n^{\circ}$ 7, de 18 de março de 2020 (dos Ministérios da Saúde e da Justiça e Segurança Pública), os protocolos de saúde para as unidades prisionais paraibanas foram definidos em um Plano de Contingência, elaborado pela Secretaria de Administração Penitenciária (SEAP), com assessoria de servidores da saúde, publicado no dia 03 de abril. O referido Plano definiu as normas para o funcionamento das 79 unidades prisionais do estado, introduzindo uma série de mudanças que impactaram o cotidiano de internos e internas, sendo a interdição das visitas e a regulamentação de "visitas virtuais" por vídeo chamadas, certamente, as duas mais impactantes (GOVERNO DA PARAÍBA/SEAP, 2020). No Quadro 1, abaixo, destacamos outras medidas adotadas.

Quadro 1: Medidas de enfrentamento à COVID-19 adotadas pelo Governo da Paraíba.

1) criação de uma unidade específica para recebimento e custódia de presos que apresentem sintomas da COVID-19; 2) utilização da Carceragem da Central de Polícia da Capital para custódia dos presos temporários da região metropolitana de João Pessoa, para que os mesmos cumpram uma quarentena mínima de 14 (catorze) dias antes de sua inserção nas Unidades Prisionais do Sistema Penitenciário da Paraíba; 3) disponibilização de uma equipe plantonista do Programa Saúde Penitenciária (PSP) para tirar dúvidas sobre os casos suspeitos; 4) aquisição de forma emergencial de insumos como máscaras e luvas para serem utilizados também pelos Policiais Penais nas unidades prisionais; 5) Autorização para fabricação própria de materiais de limpeza (desinfetantes e água sanitária) com a colaboração dos internos; 6) Reforço na alimentação dos apenados, com aumento em mais de 30\% no fornecimento de alimentos com balanceamento nutricional, auxiliando na manutenção da imunidade; 7) Distribuição dos medicamentos indicados pela Organização Mundial da Saúde para tratar os sintomas do novo Coronavírus, nas unidades prisionais; 8) Aquisição de termômetros de infravermelho que são usados para detectar quadros de febre entre os reclusos; 9) Intensificação da limpeza das celas e ambientes coletivos; 10) Realização de pequenas palestras de conscientização nas unidades penais para os servidores e reeducandos sobre a importância da higienização das mãos e utilização de EPIs; 11) Constituição de comissão multidisciplinar para notificação e acompanhamento de casos confirmados e suspeitos de da COVID-19 entre servidores da SEAP.

Fonte: Elaboração própria a partir de Plano de Contingência da SEAP-PB.

Ainda que não tenha sido possível avaliarmos ou analisarmos o cumprimento e a efetividade de tais medidas, o baixo quantitativo de adoecimento e morte por COVID-19 nas unidades prisionais do Estado é um indicador nesse sentido. Até o dia 07 de setembro de 2020, havia sido registrado 260 casos de COVID-19 entre pessoas presas na Paraíba, com 02 (dois) óbitos confirmados. Entre os trabalhadores do sistema prisional paraibano, foram registrados para o mesmo período o total de 158 profissionais contaminados e 01 (um) óbito. 
Rev. Interd. em Cult. e Soc. (RICS), São Luís, v. 6, n. 2, p. 120-141, jul./dez. 2020 ISSN eletrônico: 2447-6498

O Quadro 2, apresentado a seguir, foi elaborado a partir dos Boletins oficiais, que trazem dados cumulativos, isto é, a soma de todos os casos registrados até a data da publicação de cada um. Porém, optamos por apresentar os casos mês a mês, deduzindo-se do total apresentado no boletim o número de casos do mês anterior. Destacamos também que, oficialmente, não houve registros de casos de COVID-19 em unidades do sistema prisional paraibano no mês de março, por isso o quadro inicia-se em abril. A consulta de sites notícias da conta de números divergentes, razão por que optamos por trabalhar com dados da SEAP$\mathrm{PB}$ e do CNJ.

Quadro 2: Pessoas contaminadas e mortes por Covid-19 no Sistema Prisional da Paraíba

\begin{tabular}{|l|c|c|c|c|c|c|}
\hline $\begin{array}{l}\text { Casos de Covid- } \\
19 \text { por categoria }\end{array}$ & $\begin{array}{c}\text { ABRIL } \\
01 / 05^{*}\end{array}$ & $\begin{array}{c}\text { MAIO } \\
31 / 05^{*} \text { e } 01 / 06^{*}\end{array}$ & $\begin{array}{c}\text { JUNHO } \\
30 / 06^{*}\end{array}$ & $\begin{array}{c}\text { JULHO } \\
31 / 07^{*}\end{array}$ & $\begin{array}{c}\text { AGOSTO } \\
07 / 09 * *\end{array}$ & TOTAL \\
\hline Agentes & 11 & 91 & 38 & 12 & 6 & 158 \\
\hline Apenados/as & $* * *$ & 41 & 163 & 28 & 28 & 260 \\
\hline TOTAL & 11 & 132 & 201 & 40 & 34 & 418 \\
\hline
\end{tabular}

Fonte: *Boletim mensal da Gerência de Ressocialização da SEAP-PB

**Boletim Semanal do CNJ - COVID-19.

*** Conforme a SEAP-PB, não foram registrados casos de Covid-19 entre detentos no mês de abril. Porém, o site de notícias G1-Paraíba e reportagens da TV Sol e do JPB1 (Globo) mencionaram o caso de um servidor que testou positivo no dia $24 / 04$ e dois presos que testaram positivo no dia seguinte, $25 / 04$.

A partir dos dados acima, observa-se que, até o dia 07/09, data de publicação Boletim do CNJ, 62,2\% das pessoas afetadas pela COVID-19 estavam presas e os outras 37,8\% eram servidores - profissionais que trabalham nas unidades prisionais. Contraditoriamente, conforme informações enviadas pela SEAP-PB ao CNJ, até 14/09, dentro das unidades penais foram realizados 137 testes para COVID-19 entre pessoas presas e 326 testes entre servidores, ou seja, 29,6\% dos testes foram feitos em pessoas presas enquanto 70,4\% em servidores, inversamente à taxa de contaminação. O total de 260 pessoas presas contaminadas corresponde ao percentual de 1,9\% da população carcerária de todo estado Paraíba.

Vale destacar que, em conformidade com as orientações do Conselho Nacional de Justiça (CNJ), como parte das medidas de prevenção à propagação da COVID-19, no mês de março de 2020, 1.528 pessoas que estavam detidas (em toda Paraíba) foram liberadas para cumprir pena domiciliar, passando a ser monitoradas com tornozeleiras eletrônicas. 
Rev. Interd. em Cult. e Soc. (RICS), São Luís, v. 6, n. 2, p. 120-141, jul./dez. 2020

ISSN eletrônico: $2447-6498$

\subsection{A Penitenciária Maria Júlia Maranhão em foco}

A Penitenciária de recuperação feminina Maria Júlia Maranhão, doravante designada pelo acrônimo PMJM, localiza-se no bairro de Mangabeira, em João Pessoa, capital do estado da Paraíba. Até o final do mês agosto de 2020, registrava-se 263 mulheres em cumprimento de pena na unidade, sendo 150 delas em regime fechado, 55 em regime semiaberto e 58 em regime aberto (pena domiciliar). Mesmo deduzindo-se o número de mulheres que estão cumprindo pena em domicílio, considerando que a capacidade máxima da penitenciária é para 140 internas, observa-se que o local está com uma lotação de 39,3\% acima de sua capacidade.

O corpo funcional da unidade penal é constituído por 54 profissionais, sendo 06 (seis) assistentes administrativos, 05 (cinco) motoristas, 14 (catorze) homens e 29 (vinte e nove) mulheres exercendo a função de agente de segurança, incumbindo-se diretamente da vigília das mulheres, em sistema de revezamento diuturnamente. Tais dados revelam, de imediato, a entrada e saída regular de pessoas diariamente na unidade prisional, sinalizando a dificuldade de controlar os riscos de contaminação e de disseminação de COVID-19 para as detentas e para os agentes de segurança e pessoal administrativo.

No 'Centro de Reeducação', como também é chamado o referido presídio feminino, as reeducandas (como os órgãos de assistência às mulheres encarceradas preferem chamá-las), são alocadas em 4 pavilhões que são organizados e denominados da seguinte forma: "pavilhão principal", também chamado pelas encarceradas de "corredor", composto por 34 celas e destinado às detentas em cumprimento de regime fechado; "pavilhão do trabalho", constituído de 4 celas, sendo uma usada para o período de "reconhecimento" (definido em cinco dias e que passou a ser de 14 dias após o início da pandemia) das recém chegadas e as demais são destinadas às mulheres que saem para trabalhar durante o dia e retornam para dormir na unidade; "Pavilhão das bonecas" ou "ateliê", que possui 4 celas, sendo uma exclusiva para detentas com nível de ensino superior (que está vazia no momento) e as demais celas para abrigar as presas que trabalham no ateliê de costura, com o projeto Castelo de Bonecas 3; "Pavilhão maternidade", onde ficam as detentas que estão grávidas e que abriga, atualmente, 3 detentas. Acreditamos que os riscos de propagação do novo Coronavírus foram minimizados por essa disposição e separação entre as mulheres que saem para trabalhar e que ficam reclusas.

\footnotetext{
3 O Projeto Castelo de Bonecas foi criado em 2012, pela diretoria da Penitenciária Feminina Maria Júlia Maranhão. O objetivo é contribuir para ressocializar as detentas através do trabalho com a produção de bonecas de pano, comercializadas em feiras de artesanato e sob encomenda. O projeto conta com o apoio do Tribunal de Justiça da Paraíba e hoje conta com a participação de 12 internas.
} 
Rev. Interd. em Cult. e Soc. (RICS), São Luís, v. 6, n. 2, p. 120-141, jul./dez. 2020

ISSN eletrônico: $2447-6498$

A unidade prisional também possui uma área administrativa, com salas para psicólogos, direção, cozinha, copa, além de auditório, capela, e áreas abertas, onde existem um jardim e uma pequena horta medicinal.

Em situação de normalidade, em conformidade com a Lei de Execução Penal, todas as internas têm direito a $2 \mathrm{~h}$ de banho de sol, de segunda a sexta-feira. No sábado, elas podem receber assistência religiosa - geralmente, de grupos ligados a igrejas neopentecostais, e no domingo, podem receber visitas de seus familiares. As que se interessam, podem participar de atividades esportivas, incluindo uma competição anual interna, durante os "Jogos das Reeducandas"4; Outras internas formam um coral denominado "Vozes Passageiras", 12 internas participam do Projeto Castelo de Bonecas, outras trabalham na cozinha e circulam controladamente nas dependências da unidade. Além da possibilidade de receber assistência religiosa, as detentas podem participar de atividades de promoção à saúde ${ }^{6}$.

Entretanto, exceto o banho de sol, que passou a ser diário, as demais atividades que dependiam da presença de pessoas externas à unidade foram suspensas devido à Pandemia. Nesse contexto, conforme relato de interlocutores dentro da unidade penal em questão, a pandemia intensificou certos transtornos, já registrados pelos profissionais de saúde que trabalham no local, tais como o aumento de ocorrência de problemas psíquicos, casos de automutilação, crises de ansiedade, os quais, conforme Pimentel (2020), muitas vezes estão relacionados com o sentimento de solidão já tão presente no encarceramento de mulheres. É certo que a situação de pandemia dificultou ainda mais o precário acesso das detentas às terapias e outras formas de suporte psicológico para fazer frente às circunstâncias por ela vivenciadas.

Outro aspecto que merece destaque foi a suspensão das atividades do Projeto "Castelo de Bonecas" e o redirecionamento da equipe para confecção de máscaras cirúrgicas, em cumprimento de medidas do Governo Estadual, o que impactou não apenas as internas diretamente envolvidas no referido projeto. Durante os cinco meses de suspensão do projeto,

\footnotetext{
${ }^{4}$ Os Jogos das Reeducandas foram criados em 2013, com o objetivo de auxiliar na reintegração das detentas e ajudar no processo de ressocialização. O torneio acontece anualmente dentro da PMJM e tem duração de uma semana. As disputas contemplam as modalidades de futebol, vôlei e atletismo. No corrente ano o torneio aconteceu uma semana antes do decreto da situação de emergência.

${ }^{5}$ Criado em 2017, através de uma iniciativa de uma professora de português que atuava na Unidade, em parceria com a direção da Penitenciária Maria Júlia Maranhão, o coral Vozes Passageiras é formado por 20 detentas e realiza apresentações no presídio e em órgãos ligados ao Governo da Paraíba.

${ }^{6}$ As "rodas de conversas" são realizadas pela Escola Técnica de Saúde da Universidade Federal da Paraíba, por meio do projeto de extensão "Promoção de saúde para mulheres privadas de liberdade: uma proposta interdisciplinar", do qual uma das autoras é colaboradora voluntária.
} 
Rev. Interd. em Cult. e Soc. (RICS), São Luís, v. 6, n. 2, p. 120-141, jul./dez. 2020 ISSN eletrônico: 2447-6498

somando-se a produção desta unidade e das outras três penitenciárias femininas do Estado (que também passaram a produzir este EPI), foram confeccionadas aproximadamente de 150 mil máscaras, as quais foram destinadas para as outras penitenciárias do Estado, sendo usadas tanto por funcionários como pelas detentas. Conforme a SEAP-PB, parte dessas máscaras foram doadas para instituições de saúde e outra parte encaminhada para os(as) familiares das detentas.

Salientamos que a fabricação de máscaras nas unidades prisionais também foi implantada em várias unidades penais de outros Estados brasileiros e também em outros países como, por exemplo, da Bélgica e da Espanha, contudo, nestes países a confecção de máscaras não foi, necessariamente, realizada apenas nas unidades prisionais femininas (EUROPEAN PRISON OBSERVATORY, 2020).

Ressaltamos que, de acordo com os dados da SEAP-PB, até 07/09, foram registrados apenas 2 casos de COVID-19 na PMJM. E 55 mulheres receberam liberação para cumprir pena domiciliar, em função da situação de pandemia.

\subsection{Visitas virtuais e comunicação na prisão durante a pandemia}

Diante das medidas de isolamento social, a comunicação e as interações via redes sociais digitais e aplicativos de conversa eletrônica tornaram-se mais que uma alternativa, uma espécie de regra durante a pandemia de COVID-19. No entanto, dentro do Sistema Prisional, o cerceamento da liberdade para a livre interação e comunicação interpessoal faz parte da pena, como já discutimos.

Nas unidades penais brasileiras, a posse e uso de telefones por detentos/detentas, bem como, o acesso à internet configura um delito, sujeito às sanções legais cabíveis. Porém, o Conselho Nacional de Justiça $(\mathrm{CNJ})$ recomendou o uso de meios alternativos para viabilizar o contato entre internos e seus familiares durante a Pandemia de COVID-19. Assim, a SEAP-PB autorizou a realização de videochamadas e estas passaram a ser a alternativa adotada nas unidades penais do Estado.

Vale ressaltar que a realização de "visitas virtuais", isto é, a comunicação entre os presos e seus familiares através de videochamadas já ocorrem em algumas penitenciárias federais $^{7}$ brasileiras desde 2010, graças a uma parceria entre a Defensoria Pública da União (DPU) e o Departamento Penitenciário Nacional (Depen).

\footnotetext{
${ }^{7}$ A Penitenciária Feminina do Distrito Federal está realizando visitais virtuais desde o mês de junho de 2019 (DEFENSORIA PÚBLICA DO ESTADO DA PARAÍBA, 2020).
} 
Rev. Interd. em Cult. e Soc. (RICS), São Luís, v. 6, n. 2, p. 120-141, jul./dez. 2020

ISSN eletrônico: $2447-6498$

Na Paraíba, em agosto de 2019, a Defensoria Pública do Estado realizou a primeira 'visita virtual' em presídios estaduais, a pedido de uma defensora da Comarca de Belém, permitindo o contato entre a mãe e seu filho - detento, que estavam separados pelo cárcere e por 310 Km de distância (DEFENSORIA PÚBLICA DO ESTADO DA PARAÍBA, 2020). Oficialmente, um convênio ${ }^{8}$ assinado entre a Defensoria Pública do estado da Paraíba com o Departamento Penitenciário Nacional (Depen), em dezembro de 2019, buscava viabilizar a realização de 'visitas virtuais' em todos os presídios estaduais para o segundo semestre de 2020. Um outro acordo $^{9}$, firmado em 18 de março deste ano, entre o Governo da Paraíba e um empresa de tecnologia prevê a implementação de sistemas de videoconferência, por meio das quais irão realizar audiências virtuais e apresentação de custodiados ao poder judiciário, sem estes tenham que sair das unidades prisionais onde estão detido. Com isso, evitar-se-á o traslado até fórum e tribunais, movimento que além de implicar em risco de fuga, constitui uma ação onerosa para o Estado (GOVERNO DO ESTADO DA PARAÍBA, 2020). Entretanto, na maioria das unidades prisionais, as salas para videoconferências ainda não estão prontas. Assim, em meio à Pandemia de COVID-19, as visitas virtuais passaram a acontecer "improvisadamente".

Na PMJM, as "visitas virtuais" passaram a correr a partir do dia 17 de abril, através de vídeos chamadas do aplicativo WhatsApp, conforme informações de interlocutores que atuam na unidade. Esses encontros virtuais ocorrem em uma sala uma sala da assistência social, sob a supervisão de um agente de segurança e com auxílio de uma psicóloga ou assistente social. Realizadas de segunda a sexta-feira, em regime de escala por pavilhão/ala, as visitas contemplam cada uma das reeducandas com pelo menos uma visita virtual semanal, durante cerca de cinco minutos - tempo definido em função da quantidade de reeducandas na unidade. Além disso, independentemente dessas medidas, a dinâmica do ir e vir dos trabalhadores lotados na unidade penal continua sendo uma forma de contato significativa com o mundo exterior. Não por acaso, existe um aparente clima de respeito e cordialidade entre esses dois grupos na unidade penal em questão, sem registros de rebeliões ou conflitos nos anos recentes.

\footnotetext{
8 O convênio assinado pela Defensoria Pública do Estado da Paraíba (DPE-PB) com o Departamento Penitenciário Nacional (Depen) visa a implantação de dois projetos dentro do sistema prisional paraibano: Visita Virtual e Acesso Efetivo à Dignidade e à Justiça (Porta de Entrada), e prevê o investimento de R\$ 1,5 milhão.

${ }^{9} \mathrm{O}$ acordo, firmado em 18/03/2020, tem um propósito mais amplo, incluindo a construção de Centros Integrados de Comando de Controle (CICC), em João Pessoa, Campina Grande e Patos, os quais serviram para monitoramento na área de segurança pública, contando com investimentos de 100 milhões de reais. As unidades prisionais para quais está previsto a construção de salas para videoconferência localizam-se em João Pessoa, Campina Grande, Santa Rita, Sapé, Guarabira, Patos, Catolé do Rocha, Cajazeiras e Sousa.
} 
Rev. Interd. em Cult. e Soc. (RICS), São Luís, v. 6, n. 2, p. 120-141, jul./dez. 2020

ISSN eletrônico: 2447-6498

\subsection{A solidariedade que transpõe os muros da prisão}

Um dos pilares da vida no cárcere são as trocas simbólicas, haja vista que, muitas necessidades das pessoas presas são supridas graças às trocas de favores intramuros e/ou à solidariedade de pessoas de fora da prisão - familiares, companheiros(as), grupos de apoio (entidades religiosas, projetos de universidades etc). Durante a Pandemia do novo Coronavírus as internas da PMJM receberam ajuda de alguns projetos e iniciativas.

O projeto humanitário "Nós por Elas", idealizado e implementado por cinco estudantes de comunicação da Universidade Federal da Paraíba, arrecadou e doou 200 kits, contendo itens de higiene pessoal: creme dental, escova de dente, sabonete e absorvente. A iniciativa incluía a realização de uma atividade dentro da unidade prisional para sensibilizar as mulheres para os cuidados com autoestima e para o empreendedorismo. No entanto, essa última ação não foi realizada devido à suspensão das visitas nos presídios, realizando-se apenas a entrega dos kits no portão da Penitenciária, no dia 08 de abril. Em 02 de julho, as internas receberam outra doação de 200 kits de higiene pessoal, desta vez de um clube de futebol feminino chamado de Pelada 19.83, contendo os mesmos itens que os kits citados anteriormente. O grupo Pelada 19.83 é formado por 30 mulheres que se reuniam, desde 2019, às sextas-feiras para jogar futebol 'society'.

Interessante destacar que tanto esta última como a primeira iniciativa foram desenvolvidas por mulheres e orientadas diretamente à PMJM, constituindo-se uma ação voluntária e pontual, não alcançando todas as mulheres que cumprem pena privativa de liberdade na Paraíba.

Salientamos que, apesar do Estado ser obrigado a fornecer itens como absorventes íntimos para mulheres em cumprimento de pena privativa de liberdade, nem sempre isso ocorre em quantidade e com a regularidade adequada, cabendo às direções das unidades prisionais controlar o acesso, em função da necessidade das internas, reservando-os, algumas vezes, para aquelas que não recebem visitas de parentes que possam fornecê-los. Esse controle é causa de situações constrangedoras e o acesso facilitado, entendido como um “privilégio". Assim, normalmente, são os familiares que fornecem e levavam itens de higiene pessoal, bem como alimentos como biscoito e doces - que não costumam constar nos cardápios dos presídios. Percebe-se, desse modo, que a suspensão das visitas agravou a situação de precariedade das mulheres encarceradas na PMJM. 
Rev. Interd. em Cult. e Soc. (RICS), São Luís, v. 6, n. 2, p. 120-141, jul./dez. 2020

ISSN eletrônico: $2447-6498$

\section{CONSIDERAÇÕES FINAIS}

A realidade do Sistema Prisional brasileiro já seria uma complexa unidade de análise para nos atermos aos gargalos históricos da nossa agenda Republicana e para (re)pensarmos certas práticas e concepções socioculturais reproduzidas, inclusive, nas ações do Estado. Ao nos debruçamos sobre a intersecção entre o referido sistema e a cultura da subordinação de gênero em nossa sociedade, focalizando os impactos da pandemia de COVID-19 no cotidiano das mulheres presas na Penitenciária Maria Júlia Maranhão, chamamos atenção, mais especificamente, para três aspectos: 1) o papel do Estado na criação e implementação de protocolos que provocaram o endurecimento da vida no cárcere, sob o argumento de salvaguardar a vida; 2) a reafirmação de padrões heteronormativos com base na dicotomia entre papeis binários de gênero; 3) a ocorrência de iniciativas solidárias extramuros, conectando mulheres que têm condições sociais e trajetórias de vida diferentes.

Em primeiro lugar, como discutimos anteriormente, dentre as medidas adotadas, ressaltamos que a suspensão das visitas (presenciais), substituídas por 'visitas virtuais' de apenas 5 minutos teve grande impacto no processo de comunicação das mulheres encarceradas. Lembramos a visitação dos familiares constituem-se uma forma de circular as informações sobre o que acontece dentro das unidades prisionais, ajudando a coibir práticas de violação dos direitos humanos. Portanto, entendemos que, por um lado, a implementação das visitas virtuais parece ser um avanço, ao passo que leva ao uso da internet dentro do Sistema Prisional, favorecendo a democratização do direito à comunicação e permitindo a interação e a manutenção de laços afetivos com os familiares independentemente do local de domicílio destes. Além disso, considerando-se o contexto de pandemia, essa medida contribui para minimizar a distância e o medo de contaminação de ambas as partes. Por outro lado, considera-se as visitas virtuais não podem substituir a visitação presencial, além de ser insuficiente devido à curta duração e à falta de uma infraestrutura adequada, já que ocorreram de forma "precária", em uma sala improvisada e não planejada para este fim, e sob supervisão direta de pessoas em posição de autoridade sob as detentas. Assim, imagina-se que essa forma de realizar a 'visita virtual' não contribui para estabelecer comunicação efetiva com a sociedade, enquanto medida de reintegração social.

Em segundo lugar, a interrupção do projeto "Castelo de Bonecas" evidencia o poder de mando do Estado frente ao dever de obediência dessas mulheres. Ademais, observa-se que 
Rev. Interd. em Cult. e Soc. (RICS), São Luís, v. 6, n. 2, p. 120-141, jul./dez. 2020 ISSN eletrônico: 2447-6498

o redirecionamento das mulheres envolvidas no projeto para produção de máscaras, que foram distribuídas em todo o Sistema Prisional e até mesmo com seus familiares, reforça o entendimento que os estabelecimentos carcerários femininos trabalham para corrigir a criminalidade feminina como se esta fosse um desvio social do papel que se supõe que as mulheres deveriam cumprir, qual seja: mães e cuidadoras da família.

Desse modo, constata-se que até mesmo nas ações do Estado, identificam-se amarras socioculturais no que tange aos papéis de gênero na sociedade brasileira. Essa interpretação encontra respaldo, inclusive, nas matérias jornalísticas, haja vista que, todos os portais de notícias da capital do Estado repercutiram a pauta da produção de máscaras pelas internas mais de uma vez, em detrimento até mesmo do acompanhamento da evolução dos casos de COVID-19 nas penitenciárias paraibanas. Efetivamente, no caso em questão, a mídia parece exaltar a eficiência do estabelecimento penal em transformar e 'devolver à sociedade' boas mães e esposas, corrigindo os desvios das mulheres daquele caminho socialmente esperado. Lembramos ainda que o referido projeto, além de ter um papel importante na socialização intramuros, é também uma alternativa para "passar o tempo" ou mesmo "ocupar a mente", como costumam dizer algumas detentas.

Em terceiro lugar, a ocorrência de doações de kits de higiene pessoal, realizadas por mulheres 'livres' para mulheres (em situação de cárcere), expressa a solidariedade e o reconhecimento das necessidades particulares das mulheres, demonstrando a conexão entre sujeitos hierárquica e desigualmente posicionados na estrutura da sociedade. Além disso, tais gestos podem ser compreendidos como um ato simbólico de comunicação, embora vertical e assimétrico, entre dois mundos: o de dentro e o de fora da prisão; o mundo das pessoas punidas com um superisolamento (encarceramento) e daquelas em situação de isolamento social (quarentena) graças às suas condições sociais e/ou seus privilégios de classe. Um diálogo em meio ao enfrentamento de uma ameaça comum - o Coronavírus, tendo por base a sororidade.

Por fim, destaca-se que os impactos da Pandemia de COVID-19 na saúde das mulheres presas na PMJM não se restringem ao risco de contágio pelo novo Coronavírus, mas tem o condão de afetar, inclusive, a saúde mental/psicológica das mesmas, uma vez que, fez-se necessário a suspensão das visitas, dos serviços de acompanhamento e assistência psicossocial, além da atuação de entidades religiosas, projetos das universidades e demais 
Rev. Interd. em Cult. e Soc. (RICS), São Luís, v. 6, n. 2, p. 120-141, jul./dez. 2020

ISSN eletrônico: $2447-6498$

instituições que, de diferentes maneiras, levam um pouco da dinâmica e das interações com "o mundo" além dos muros da prisão.

\section{REFERÊNCIAS}

BARATTA, A. Criminologia crítica e crítica do direito penal: introdução à sociologia do direito penal. $2^{\text {a }}$ Ed. Rio de Janeiro: Freitas Bastos, 1999.

BARROS, Vanessa Andrade de ; BARROS, Carolyne Reis; MÁXIMO, Thaís Augusta de Oliveira. Trabalhar nas prisões em tempos de pandemia: questões para reflexão. In: Guimarães, Ludmila de Vasconcelos M. ; Carreteiro, Teresa Cristina; Nasciutti, Jacyara Rochael (Orgs.) Janelas da Pandemia - Belo Horizonte: Editora Instituto DH, 2020

BRASIL. Presidência da República. Lei de Execução Penal nº 7.210, de 11 de julho de 1984. Disponível em: http://www.planalto.gov.br/ccivil_03/leis/17210.htm. Acesso em: 02 abril 2020.

BRASIL. Ministério da Justiça. Secretaria Nacional de Justiça (Org). Normas e princípios das Nações Unidas sobre prevenção ao crime e justiça criminal. Brasília: Secretaria Nacional de Justiça, 2009.

BRASIL. Ministério da Justiça. Departamento Penitenciário Nacional; PNUD. Modelo de Gestão para a Política Prisional. PNUD/Ministério da Justiça: Brasília, 2016.

BRASIL. Ministério da Saúde; Ministérios da Justiça e Segurança Pública. Portaria Interministerial $n^{o} 7$, de 18 de março de 2020. Diário Oficial da União. Disponível em: https://www.in.gov.br/en/web/dou/-/portaria-interministerial-n-7-de-18-de-marco-de-2020248641861 Acesso em: 15 Ago 2020.

CONSELHO NACIOANL DE JUSTIÇA (CNJ); DEPEN. Boletim Semanal CNJ Covid-19. Disponível em: https://www.cnj.jus.br Acesso em 17 Set. 2020

DECLARAÇÃO UNIVERSAL DOS DIREITOS HUMANOS. UNIC/RIO/005, Janeiro 2009. (DPI/876). Disponível em: https://nacoesunidas.org/wp-content/uploads/2018/10/DUDH.pdf Acesso em: 15 Abril 2020.

DEFENSORIA PÚBLICA DO ESTADO DA PARAÍBA. Famílias da Paraíba poderão fazer videochamadas com parentes presos. Reportagem de Matheus Wendell. Disponível em: https://defensoria.pb.def.br/noticias.php?idcat=1\&id=2129 Acesso em: 11 de set. de 2020.

DEPEN. Departamento Penitenciário Nacional. Levantamento de Informações penitenciárias/INFOPEN, 2019. Disponível em: https://www.gov.br/depen/pt-br . Acesso em 13 de setembro de 2020.

DEPEN. Relatório Temático Sobre Mulheres Privadas de Liberdade. Disponível em: https://www.gov.br/depen/pt-br . Acesso em 05 de maio de 2020. 
Rev. Interd. em Cult. e Soc. (RICS), São Luís, v. 6, n. 2, p. 120-141, jul./dez. 2020

ISSN eletrônico: 2447-6498

DEPEN. Painel de Monitoramento da COVID-19 no Sistema Prisional. Disponível em: https://www.gov.br/depen/pt-br Acesso em: 22 Set 2020.

EUROPEAN PRISON OBSERVATORY. COVID-19: ¿Qué está pasando en las cárceles europeas? Marzo de 2020. Disponível em: https://leasur.cl/1058-2/ Acesso em: 08 Jul 2020

FOUCAULT, Michel. Vigiar e Punir: Nascimento da prisão- História da violência nas prisões. tradução de Raquel Ramalhete. Petrópolis, Vozes, 1987. 288p. Petrópolis: Editora Vozes, 1987.

GLOBO ESPORTE. Portal de Notícias G1. Penitenciária feminina realiza evento esportivo entre as Detentas. Disponível em: https://globoplay.globo.com/v/8391378/ Acesso em 5 de ago. de 2020.

GOVERNO DA PARAÍBA; SECRETARIA DE ESTADO DA ADMINISTRAÇÃO PENITENCIÁRIA DA PARAÍBA. Plano de Contingência para o novo coronavírus (covid19) no Sistema Penitenciário do Estado da Paraíba. Disponível em: https://paraiba.pb.gov.br/ Acesso em: 08 Ago 2020.

GOVERNO DE ESTADO DA PARAÍBA; SECRETARIA DE COMUNINCAÇÃO (SECOM). Penitenciárias terão sistemas de videoconferência e reforço no monitoramento por câmeras. Disponível em: https://paraiba.pb.gov.br/ Acesso em: 15 Set. 2020

GOVERNO DE ESTADO DA PARAÍBA. Revista Seap em Ação. Ano I. Edição Especial, Ju/Ago 2020.

HASSEMER, Winfried. Introdução aos fundamentos do Direito Penal. Porto Alegre, 2005.

INFOPEN. Levantamento de Informações penitenciárias, INFOPEN, Mulheres. Organização Thandara santos. Colaboração Marlene Inês da Rosa [et all]. Ministérios da Justiça e Segurança Pública; Departamento Penitenciário Nacional. 2ª Edição. Brasília, 2017.

INSTITUTO DE PESQUISA ECONÔMICA APLICADA. (Texto para discussão 2095) O desafio da reintegração social do preso: uma pesquisa em estabelecimentos prisionais. Brasília/Rio de Janeiro: Ipea, 2015.

LEMGRUBER, Julita. "Cemitério dos vivos: análise sociológica de uma prisão de mulheres". 2. " ed., Rio de Janeiro: Forense, 1999.

LIMA, G. M. B.; PEREIRA NETO, A. F.; AMARANTE, P. D. C.; DIAS, M. D.; FERREIRA FILHA, M. O. "Mulheres no cárcere: significados e práticas cotidianas de enfrentamento com ênfase na resiliência; Saúde em Debate"; Rio de Janeiro, v. 37, n. 98, p. 446-456, jul/set 2013.

ONU. Regras mínimas para o tratamento de prisioneiros. Disponibilizado em: Acesso em: 21 jul. 2016. 
Rev. Interd. em Cult. e Soc. (RICS), São Luís, v. 6, n. 2, p. 120-141, jul./dez. 2020 ISSN eletrônico: $2447-6498$

PERANO, J. (Neo) Liberalismo y Control Socio Penal. Algunas reflexiones. Revista Pensamiento Penal [digital], 2019. Acesso em: 24 de ago, 2020. Disponível em: http://www.pensamientopenal.com.ar/doctrina/48437-neo-liberalismo-y-control-socio-penalalgunas-reflexiones

PIMENTEL, Elaine. Aprisionamento de mulheres em tempos de pandemia de Covid-19. In: Guimarães, Ludmila de Vasconcelos M. ; Carreteiro, Teresa Cristina ; Nasciutti, Jacyara Rochael (Orgs.) Janelas da Pandemia - Belo Horizonte : Editora Instituto DH, 2020.

QUEIROZ, Nana. Presos que menstruam. 1. ed. - Rio de Janeiro: Record, 2015.

RUDNICKI, Dani; VEECK, Matheus Oliveira. Sobre o direito à comunicação e o acesso dos presos à internet. Revista Brasileira de Sociologia do Direito, v. 5, n. 2, mai./ago. 2018. Disponível em: http://revista.abrasd.com.br/index.php/rbsd/article/view/206. Acesso em: 04 abril 2020.

SEN, Amartya. Desenvolvimento como Liberdade. Tradução: Laura Teixeira Motta. São Paulo: Companhia das Letras, 2000.

MDH. Ministério da Mulher, da Família e dos Direitos Humanos. "Racismo institucional é tema de Audiência Pública do Conselho Nacional dos Direitos Humanos". https://www.gov.br/mdh/pt-br/ Acesso em 13-09-2020.

MJSP. Ministério da Justiça e Segurança Pública. "DEPEN atualiza dados sobre a população carcerária no Brasil". Disponível em: https://www.gov.br/mj/pt-br/assuntos/noticias/depenlanca-paineis-dinamicos-para-consulta-do-infopen-2019. Acesso em 13-09-2020. 